Article

\title{
Thermal Sensitive Shape Memory Behavior of Epoxy Composites Reinforced with Silicon Carbide Whiskers
}

\author{
Yongkun Wang *, Wenchao Tian, Xiaohan Liu and Junjie Ye \\ Key Laboratory of Ministry of Education for Electronic Equipment Structure Design, Xidian University, \\ Xi'an 710071, China; wctian@xidian.edu.cn (W.T.); xiaohanliu@stu.xidian.edu (X.L.); jjye@xidian.edu.cn (J.Y.) \\ * Correspondence: ykwang@xidian.edu.cn; Tel.: +86-29-8820-2954
}

Academic Editor: Jinlian Hu

Received: 5 December 2016; Accepted: 16 January 2017; Published: 21 January 2017

\begin{abstract}
A novel shape memory polymer composite was fabricated by introducing various amounts of silicon carbide whiskers ( $\mathrm{SiCws}$ ) into a shape memory epoxy. The relationship between the thermomechanical properties of the system and structural changes were investigated via dynamic mechanical analysis, scanning electron microscopy, and bending tests. The results show that the bend strength of composites can improve by $64.1 \%$ when $\mathrm{SiCw}$ content reaches $12 \mathrm{wt} \%$. The shape transition temperatures of $\mathrm{SiCw}$ /epoxy composites decreased slightly with the increase in $\mathrm{SiCw}$ content, but it was noted that all of the composites showed excellent shape memory properties. The shape fixity ratio increased as $\mathrm{SiCw}$ content increased $(>99 \%)$, and the shape recovery ratio slightly decreased as $\mathrm{SiCw}$ content increased $(>95 \%)$. All of the composites nearly recovered to their original shape within $2 \mathrm{~min}$ (not 100\%), and the shape recovery speed significantly improved at a higher temperature. It is anticipated that tagging products will be used in the aerospace industry.
\end{abstract}

Keywords: silicon carbide whiskers; hydro-epoxy; mechanical properties; shape memory behavior

\section{Introduction}

Shape memory polymers (SMPs) are stimuli-responsive materials that can assume a temporary shape and recover their original shape when triggered through an external stimulation such as thermal stimulus, electric current, light, magnetic field, moisture, and $\mathrm{pH}$ value [1-8]. Thermally induced SMPs are the most common type of SMP. Compared to shape memory alloys and shape memory ceramics, SMPs have been widely researched due to their facile processability, low cost, appreciable shape recovery, and broad range of shape recovery temperatures [9-12]. Therefore, they are ideal candidates for potential applications in intelligent biomedical materials, heat shrinkable packaging, smart textile, aeronautics, astronautics, sensors and actuators, information carriers, disassembly concepts, and supervision technologies for cooling chains [13-21].

Though outstanding in some aspects compared with shape memory alloys and shape memory ceremics, SMPs have obvious shortcomings: low mechanical strength and shape recovery stress. The recovery stress of shape memory alloys can reach as high as 800 megapascals, but the recovery stress of SMPs is usually from a few tenths of a megapascal to a few tens of megapascals. In order to solve this problem, considerable efforts have been made. However, until today, the immediate method has been using high modulus inorganic or organic fillers to reinforce the pristine SMPs. In the past few years, carbon materials, including carbon black, carbon fiber, carbon nanotubes, and graphene, have been widely applied in polymer composites. Ma et al. [22] filled shape memory polyethylene with carbon black to prepare two-way reversible shape memory polymer composites. In the composites, the additional of carbon black nanoparticles has had a beneficial effect on performance in the two-way 
shape memory effect, and carbon black increased the tensile modulus in the rubbery. Park et al. [23] reinforced shape memory polyurethane with graphene and found that graphene effectively reinforced polyurethane and improved the shape recovery of an SMP composite.

In general, there are two types of SMPs: thermoplastic and thermoset SMPs. Compared with thermoplastic SMPs, thermoset SMPs exhibit a much higher stiffness and dimensional stability, and have better environmental durability. Therefore, thermosetting SMPs have received much of the attention among researchers and are commonly used as matrix materials in structural composites for their high stiffness and shape recovery force. However, the studies have been mostly conducted in tension mode. In the current work, silicon carbide whiskers ( $\mathrm{SiCws)} \mathrm{were} \mathrm{used} \mathrm{to} \mathrm{fill} \mathrm{a} \mathrm{hydro-epoxy}$ resin to prepare a shape memory polymer composite. SiCws usually act as reinforcement phases to improve the property of a polymer-matrix due to their exceptional mechanical properties, low weight, high aspect ratio, high elastic modulus, chemical stability, and high thermal shock resistance [24-26]. Moreover, epoxy resins have been associated with a high modulus and strength, and have been widely studied and used in many kinds of structural composites [27]. Therefore, SiCws were chosen as the reinforcing phase to fill the shape memory epoxy resin. The effect of the SiCws on the mechanical properties, thermal properties, and shape memory performance of $\mathrm{SiCw} /$ hydro-epoxy composites were investigated.

\section{Experimental}

\subsection{Materials}

The hydro-epoxy (AL3040, epoxy value is $0.43 \mathrm{eq} / 100 \mathrm{~g}$ ) was produced by Yantai Aolifu Chemical Industry Co., Ltd. (Yantai, China). The curing agent methyl tetrahydro-phthalic anhydride (MeTHPA, molecular weight is $166.181 \mathrm{Da}$ ) was purchased from Xi'an Hangang Chemical Co., Ltd. (Xi'an, China). The accelerant agent 2,4,6-tris(dimethylaminomethyl) phenol (DMP-30, Molecular weight is $265.4 \mathrm{Da}$ ) was provided by Guangzhou Kay Trade Co., Ltd. (Guangzhou, China). Silicon carbide whiskers (SiCws, $\beta$-SiC whisker, $0.05-2.5 \mu \mathrm{m}$, length: diameter $\geq 20$, purity $\geq 99 \%$ ) were supplied by Xuzhou Hong Wu Nanomaterials Co., Ltd. (Xuzhou, China). These materials were used without further purification.

\subsection{Preparation of Shape Memory SiCw/Hydro-Epoxy Composites}

The samples were fabricated by incorporating different contents of high purity SiCws $(4,8,12$, and $16 \mathrm{wt} \%$ ) into hydro-epoxy resin. Firstly, the SiCws were treated with a silane coupling agent KH-560 for surface treatment. Secondly, a certain proportion of hydro-epoxy and SiCws was stirred evenly at $80^{\circ} \mathrm{C}$, MeTHPA and DMP-30 (the weight ratio of hydro-epoxy /MeTHPA/DMP-30 = 100:80:0.8) were mixed in, and the mixture was then stirred with a magnetic stirrer until the mixture was evenly mixed. After that, the mixtures were sonicated by an ultrasonic dispersion instrument for 20 min. Finally, the mixture was poured into a glass mold for curing, and the curing temperature process was $80^{\circ} \mathrm{C} / 1 \mathrm{~h}+$ $110^{\circ} \mathrm{C} / 3 \mathrm{~h}+150{ }^{\circ} \mathrm{C} / 2 \mathrm{~h}$.

\subsection{Experimental Methods}

In order to investigate the influence of $\mathrm{SiCw}$ content on the mechanical properties of $\mathrm{SiCw} /$ hydro-epoxy composites, blend tests at room temperature were performed with a SANS tester (Shenzhen SANS Material Test Instrument Co. Ltd., Shenzhen, China) according to ASTM D7264.

The SiCw/hydro-epoxy composites were cut into pieces of $4 \times 20 \times 20 \mathrm{~mm}^{3}$ and tested with a thermal constant analyzer (Hot-Disk, AB Company, Bern, Switzerland).

The SiCw/hydro-epoxy composites were cut into $5 \times 10 \times 30 \mathrm{~mm}^{3}$, and the samples were sanded with 800 grit sandpaper (Shandong Lianjie Engineering Materials Co., Ltd., Jinan, China). DMA was performed in a single cantilever clamping fixture and carried out using a Q800 (TA instruments 
company, New Castle, DE, USA). The temperature was increased to $180{ }^{\circ} \mathrm{C}$ from $20^{\circ} \mathrm{C}$ at a rate of $5{ }^{\circ} \mathrm{C} / \mathrm{min}$, and the amplitude and dynamic load were $10 \mathrm{um}$ and $1 \mathrm{~Hz}$, respectively.

The specimens were frozen in liquid nitrogen and then brittle-fractured. The broken surfaces were sputter-coated with gold and observed with a SEM (INCA X-ACT, Tescan, Brno, Czech Republic).

Rectangular samples $\left(100 \times 10 \times 3 \mathrm{~mm}^{3}\right)$ were cut to investigate the thermo-active shape memory effect of the $\mathrm{SiCw} /$ hydro-epoxy composites. Shape memory performance of the composites were tested as follows: (i) in an oven, the samples were heated to the glass transition temperature $\left(T_{\mathrm{g}}\right)$ and held for $5 \mathrm{~min}$; (ii) the samples were bent into a " $U$ " shape and then quickly dipped into ice water, the angle recovery of the " $U$ " shape was measured, and the shape fixity ratio $\left(R_{\mathrm{f}}\right)$ was tested; (iii) the " $U$ "-shaped samples were placed into the oven, and the temperature of the oven was set to $T_{\mathrm{g}}, T_{\mathrm{g}}+10^{\circ} \mathrm{C}$, and $T_{\mathrm{g}}+20^{\circ} \mathrm{C}$ of the composites; (iv) the shape recovery process of the composites was observed, and, when the shape of the samples did not change, the recovery time was recorded. Figure 1 shows the shape memory model. The shape memory recovery speed is defined as $\theta_{\mathrm{i}} / t$, and the shape recovery ratio $\left(R_{\mathrm{r}}\right)$ is defined as $\left(\theta_{\mathrm{i}}-\theta_{\mathrm{f}}\right) / \theta_{\mathrm{i}} \times 100 \%$ [28], where $\theta_{\mathrm{i}}$ is the deformation angle $\left({ }^{\circ}\right), t$ is the recovery time, and $\theta_{\mathrm{f}}$ is the angle of recovery after deformation.

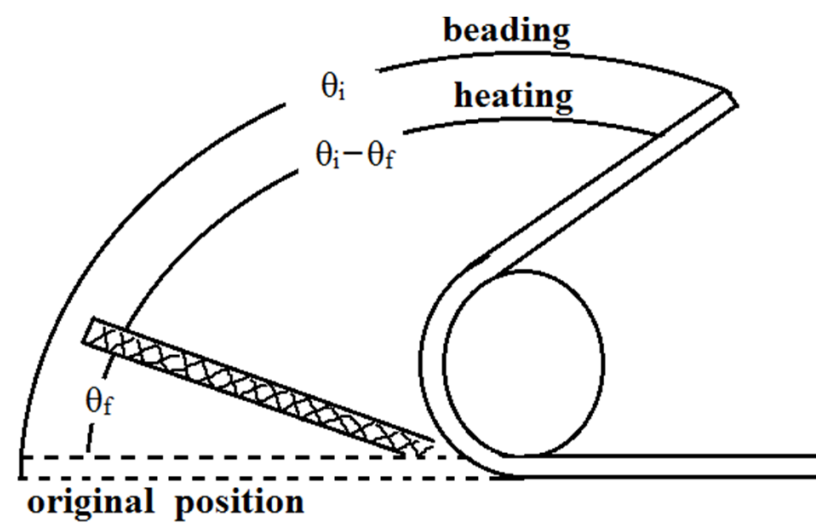

Figure 1. Shape memory model.

\section{Results and Discussions}

\subsection{Mechanical Properties}

The bending strength and tensile strength are the most important indicators revealing the mechanical property of $\mathrm{SiCw} /$ hydro-epoxy composites. The relationship between mechanical properties and $\mathrm{SiCw}$ content is shown in Figures 2 and 3. From Figure 2, it can be found that, with the increase in $\mathrm{SiCw}$ content, the bending strength of the $\mathrm{SiCw} /$ hydro-epoxy composites increases when the SiCw content is less than $12 \mathrm{wt} \%$. The bending strength of the bulk specimen is $72.2 \mathrm{MPa}$, and the bending strength of sample with $12 \mathrm{wt} \% \mathrm{SiCw}$ increases by $64.1 \%$ compared to the $0 \mathrm{wt} \%$. Figure 3 reveals that the tensile strength of $\mathrm{SiCw} /$ hydro-epoxy composites increases first and then decreases with the increase in $\mathrm{SiCw}$ content. When the content of the $\mathrm{SiCw}$ content is less than $8 \mathrm{wt} \%$, the tensile strength of the $\mathrm{SiCw} /$ hydro-epoxy composites increases linearly with the increase in $\mathrm{SiCw}$ content. However, the tensile strength increases significantly when the $\mathrm{SiCw}$ content rises to $12 \mathrm{wt} \%$, and the tensile strength increases about $77.16 \%$ compared with the bulk specimen. However, the tensile strength decreases when the $\mathrm{SiCw}$ content increases to $16 \mathrm{wt} \%$. This shows that the $\mathrm{SiCw}$ content should be such that the mechanical properties of the $\mathrm{SiCw} /$ hydro-epoxy composites are improved.

Considering the effect of $\mathrm{SiCw}$ reinforment, the bending strength of the composites will increase [29]. However, it was noted that the bending strength of the sample with $16 \mathrm{wt} \% \mathrm{SiCw}$ decreased significantly; this is due to the proper amount of $\mathrm{SiCw}$ can not only strengthen the matrix but also make up the micro defects present in the pure epoxy resin, which can effectively transfer the stress, prevent the crack growth, and improve the mechanical properties of the pure epoxy resin. 
However, too many SiCws will increase the viscosity of epoxy resin. It is easy to produce bubbles and other defects and destroy the continuous structure of epoxy resin matrix.

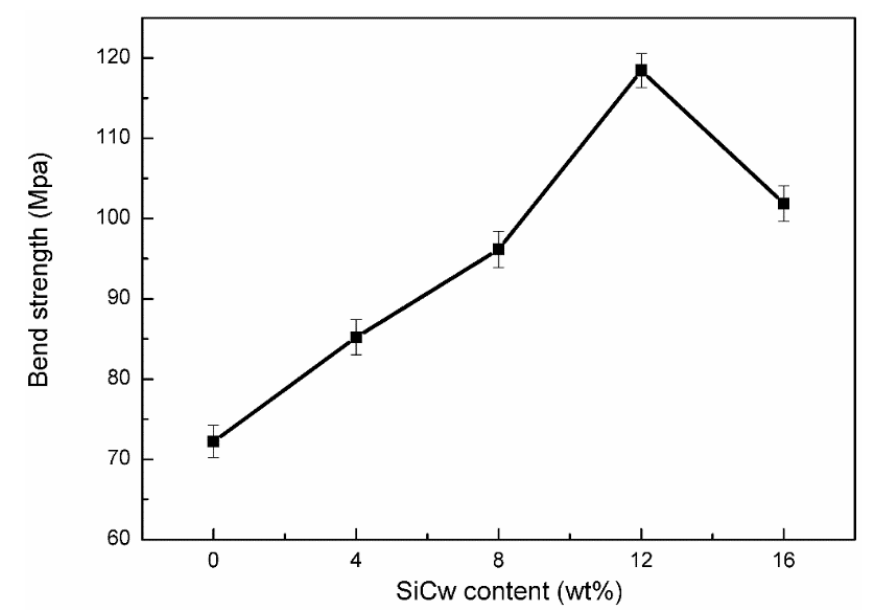

Figure 2. Bending strength of the $\mathrm{SiCw} /$ hydro-epoxy composites.

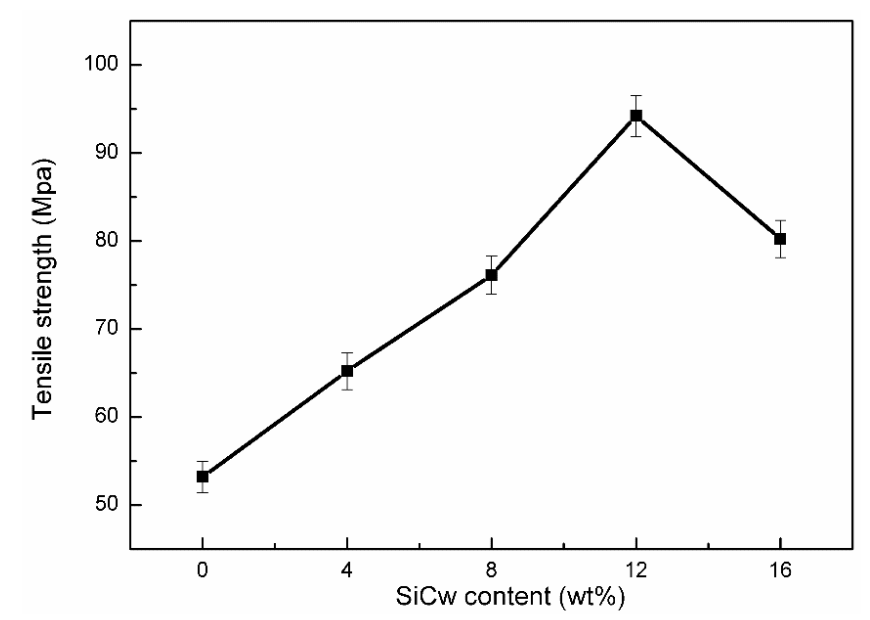

Figure 3. Tensile strength of the $\mathrm{SiCw} /$ hydro-epoxy composites.

\subsection{Thermal Properties Analyses and SEM}

Thermal conductivity is one of the key factors for shape memory composites, and the high thermal conductivity favors a reduction in the shape recovery time of the SiCw/hydro-epoxy composites. Figure 4 reveals that the thermal conductivity of the composites was improved with the addition of $\mathrm{SiCw}$ filler, and the thermal conductivity increased with increasing $\mathrm{SiCw}$ content. This is because, when $\mathrm{SiCw}$ content is low, few SiCws are in contact with each other, and thermal conductivity is slightly improved [30]. However, with an increase in $\mathrm{SiCw}$ content ( $>12 \mathrm{wt} \%)$, the probability of the thermal conductivity chain and thermal conductivity network increased. Thus, the thermal conductivity increased significantly.

Dynamic mechanical analysis (DMA) is can not only be used to characterize the mechanical properties of polymers in different temperature fields, but also characterize the glass transition temperature of $T_{\mathrm{g}}$. The $T_{\mathrm{g}} \mathrm{s}$ of the $\mathrm{SiCw} /$ hydro-epoxy composites are the peaks of the tan $\delta$ curves, as shown in Figure 5. The storage modulus of the $\mathrm{SiCw} /$ hydro-epoxy composites are shown in Figure 6. $T_{\mathrm{g}}$ is an important parameter of the themomechanical properties and the shape memory effect of shape memory polymer composites. In this work, the shape memory transition temperature is glass transition temperature $\left(T_{\mathrm{g}}\right)$. From Figure 5 , it can be found that the $T_{\mathrm{g}}$ values of the $\mathrm{SiCw} /$ hydro-epoxy 
composites slightly decrease with increasing $\mathrm{SiCw}$ content. This phenomenon is due to the addition of the whiskers, reducing the crosslinking density of the epoxy resin, and increasing the peristalsis ability of the molecular chain in the curing network, which leads to the decrease in the $T_{\mathrm{g}}$ values of the $\mathrm{SiCw} /$ hydro-epoxy composite.

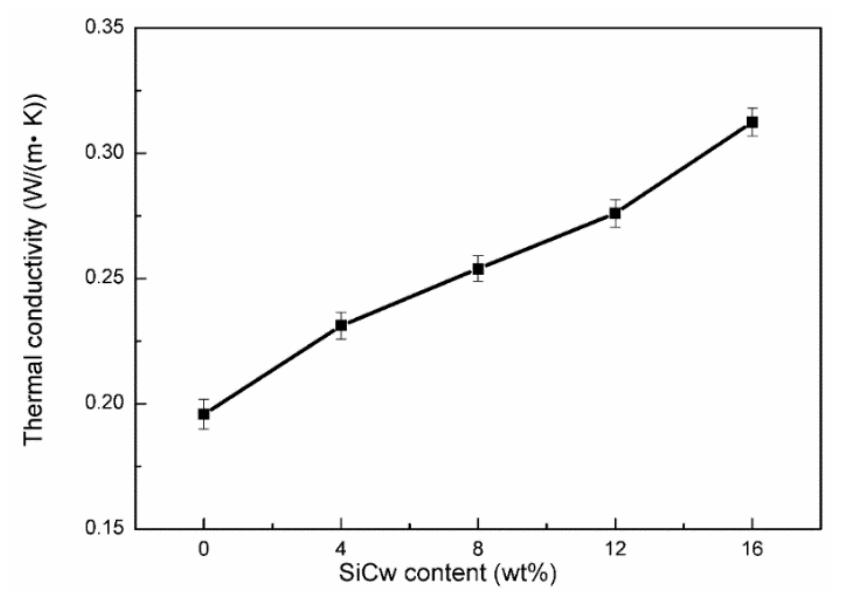

Figure 4. Thermal conductivity of $\mathrm{SiCw} /$ hydro-epoxy composites with different $\mathrm{SiCw}$ amounts.

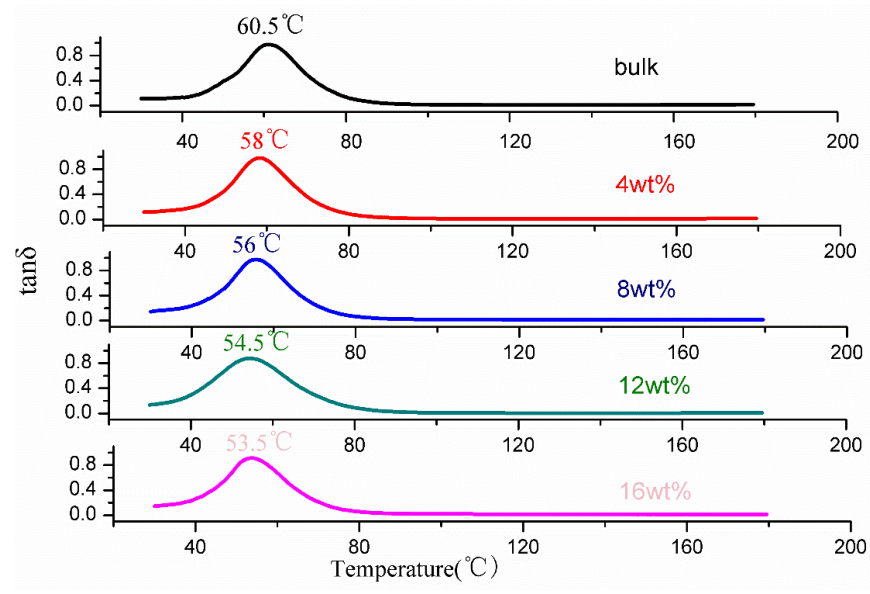

Figure 5. Tan $\delta$ curves of SiCw/hydro-epoxy composites.

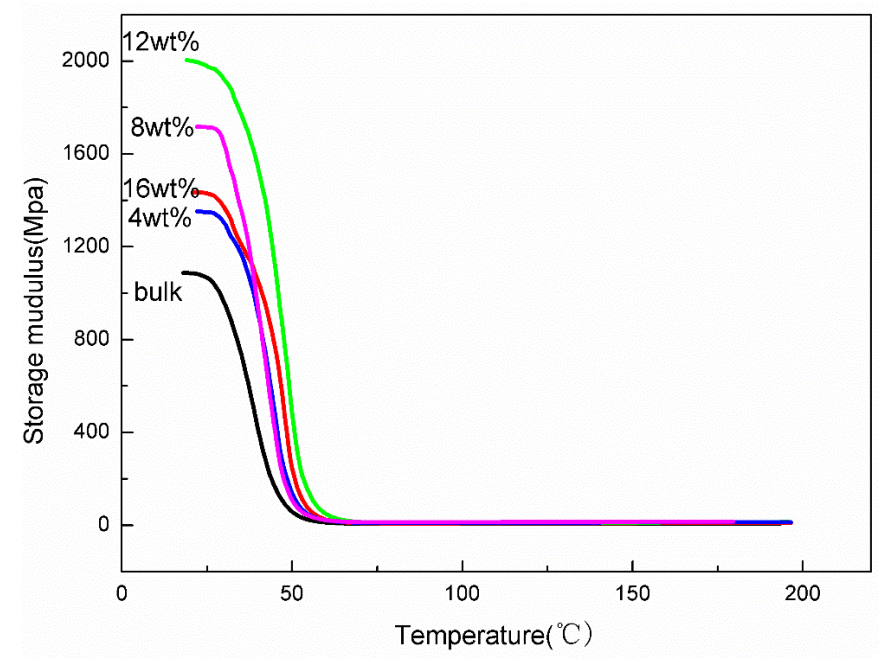

Figure 6. Storage modulus of $\mathrm{SiCw} /$ hydro-epoxy composites. 
The storage modulus below the shape memory transition temperature is related to the shape fixity ratio of the composites, and the storage modulus above the shape memory transition temperature is related to the shape recovery ratio [31]. It also can be found in Figure 6 that the storage modulus increases with the increase in $\mathrm{SiCw}$ content but decreases when $\mathrm{SiCw}$ content rises to $16 \mathrm{wt} \%$. For further analysis, the SEM images of the samples were observed. Figure 7 indicates that, when $\mathrm{SiCw}$ content is lower than $12 \mathrm{wt} \%$, the whiskers are dispersed in the matrix, and the whiskers cannot contact each other. The interface between the SiCws and the hydro-epoxy resin is smooth, and the fracture surface is ductile fracture. Therefore, the mechanical properties and thermal conductivity of the composites insignificantly improved. When the whisker content increased to $12 \mathrm{wt} \%$, the SiCw network structure was formed in the composites, which can be useful in improving the mechanical properties and thermal conductivity of composites; however, higher SiCw content ( $\mathrm{w} \geq 16 \mathrm{wt} \%)$ caused a serious aggregation that resulted in bubbles in the matrix, which destroy the continuous structure of the resin. Thus, the mechanical properites of the composites decreased.

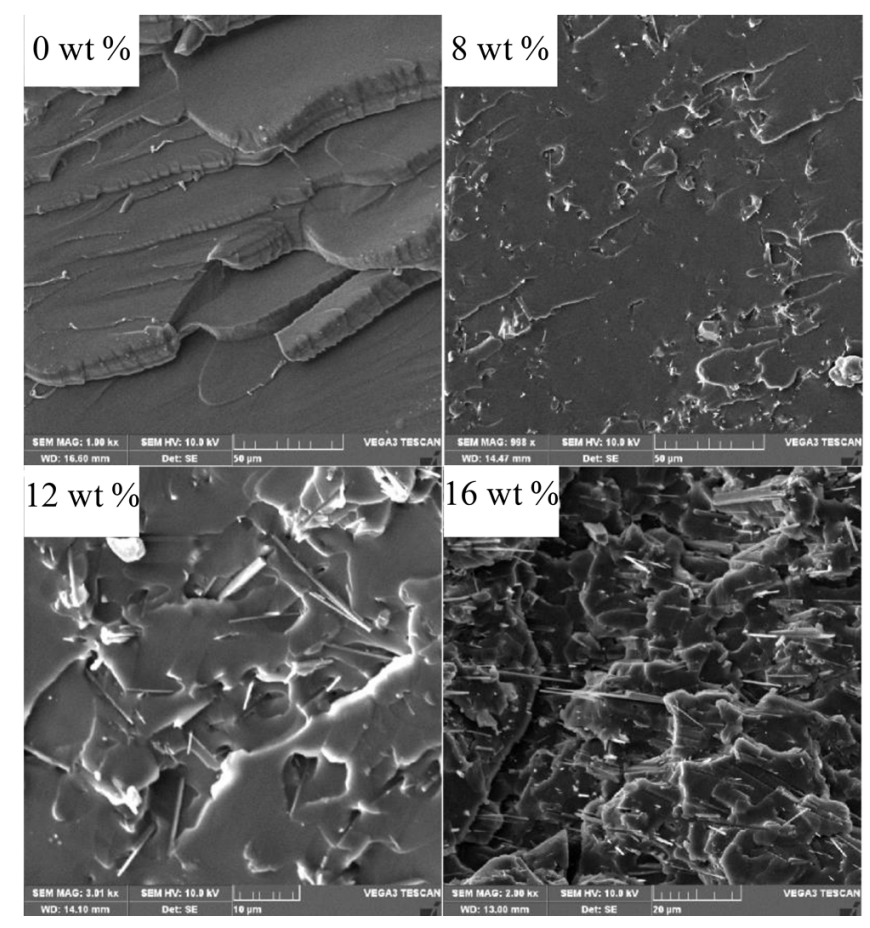

Figure 7. SEM of the SiCw /hydro-epoxy composites.

\subsection{Shape Memory Property Analysis}

Through the DMA analysis, it can found that the SiCw has a passive effect on the shape fixity ratio. However, because the $\mathrm{SiCw}$ does not have shape memory behavior, there is no doubt that the $\mathrm{SiCw}$ has a negative effect on the shape recovery ratio of the $\mathrm{SiCw} /$ hydro-epoxy composite. In order to analyze the effect of $\mathrm{SiCw}$ content on the shape memory properties of the hydro-epoxy system, we tested the shape memory performance of the $\mathrm{SiCw} / \mathrm{hydro}$-epoxy composite. The results are shown in Table 1, revealing that, with the increase in $\mathrm{SiCw}$ content in the shape memory composites, the shape recovery speed slightly decreased, the shape fixity ratio improved, and the shape recovery ratio significantly decreased. However, the shape recovery ratio of all samples was more than $95 \%$, which indicates that the $\mathrm{SiCw} /$ hydro-epoxy composite is an excellent shape memory polymer composite. Figure 8 shows the shape memory process of a specimen with $8 \mathrm{wt} \% \mathrm{SiCw}$. Starting from the original shape, the specimen is deformed into a $U$ shape in the oven. Upon cooling under load, the deformed temporary shape is fixed. Then, placing the specimen in the $56^{\circ} \mathrm{C}$ oven, full recovery was observed after only $75 \mathrm{~s}$. 
Table 1. Effect of SiCw content on the shape memory properties of the hydro-epoxy system.

\begin{tabular}{cccccc}
\hline Sample & Bulk & $\mathbf{4} \mathbf{w t} \%$ & $\mathbf{8} \mathbf{w t} \%$ & $\mathbf{1 2} \mathbf{~ w t} \%$ & $\mathbf{1 6} \mathbf{w t} \mathbf{~}$ \\
\hline $\mathrm{Vr}^{\circ} / \mathrm{s}$ & 3.21 & 2.65 & 2.4 & 2.07 & 1.82 \\
$R_{\mathrm{f}} / \%$ & 98.5 & 99.3 & 99.8 & 100 & 100 \\
$R_{\mathrm{r}} / \%$ & 99.7 & 99.2 & 98.4 & 97.6 & 95.7 \\
\hline
\end{tabular}

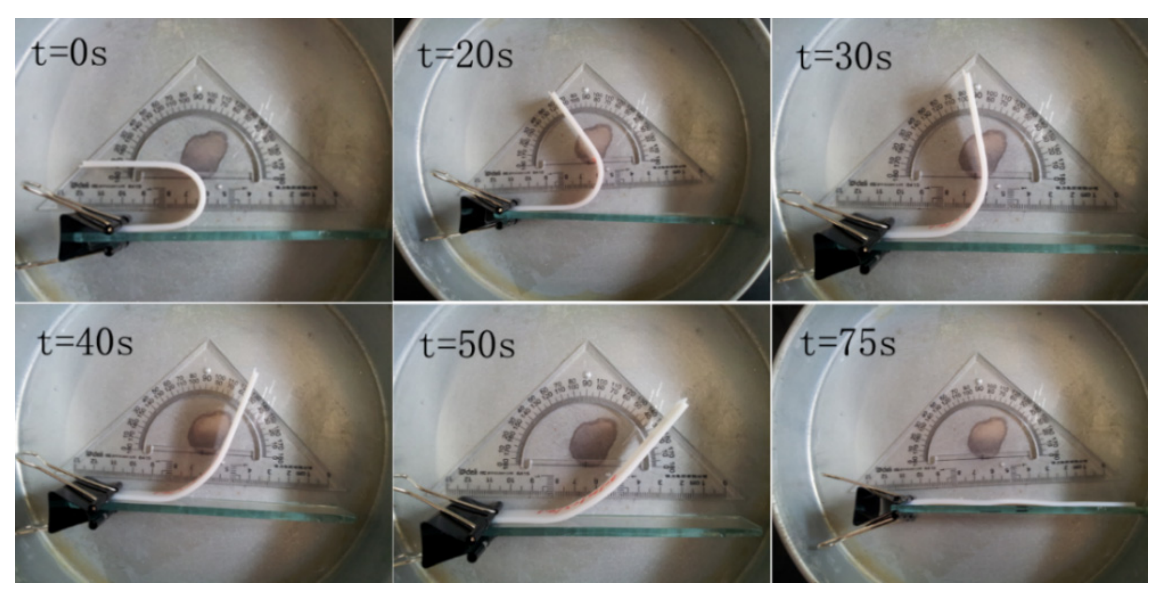

Figure 8. Shape memory process of the hydro-epoxy composites with $8 \mathrm{wt} \% \mathrm{SiCw}$ at $56{ }^{\circ} \mathrm{C}$.

In fact, the shape memory effect of the polymer composite is determined by two factors. One is the external condition [32]. These external conditions include the deformation amplitude, the velocity of deformation, deformation temperature, temporary fixed time, cooling rate, and deformation response times. Different conditions cause different shape memory effects. The other is the structure of the polymer composite [33]. Therefore, it is very important to control the external conditions of the shape memory polymer composites when the polymer has the same structures. In this work, we mainly analyzed the effect of the deformation temperature and cycle times on the shape memory performance of the $\mathrm{SiCw} /$ hydro-epoxy composites.

The sample with $12 \mathrm{wt} \% \mathrm{SiCw}$ was used to investigate the effect of the deformation temperature on the shape memory effect of the $\mathrm{SiCw} /$ hydro-epoxy composite, as shown in Figure 9. According to the results, the slope of the curves is generally larger from $60^{\circ}$ to $120^{\circ}$. This indicates that the shape recovery rate is high. However, the specimens have a relative low recovery rate at the initial and final stages. This increase is because, during the initial stage, the specimen needs time to increase temperature to that of the shape memory transition. The molecular chain slowly begins to creep, and the frozen stress begins to release gradually. After that, the frozen stress releases rapidly, and the shape recovery speed significantly increases. However, during the final stage, there is little frozen stress in the specimen, and the recovery rate thus becomes slow again.

Figure 10 shows the effect of the cycling number on the recovery ratio of SiCw/hydro-epoxy composites. It can be found that the shape recovery ratio of composites slightly decreases with increasing cycling number. However, the shape recovery ratio was gradually balanced when the cycling number was higher than 5 . This phenomenon is attributed to the accumulation of plastic deformations in the composites, which inevitably occurs during the recovery process. Moreover, when the deformation occurs more than 5 times, the change in the shape recovery ratio is small, which is due to the stability of the molecular chain and plastic deformations. 


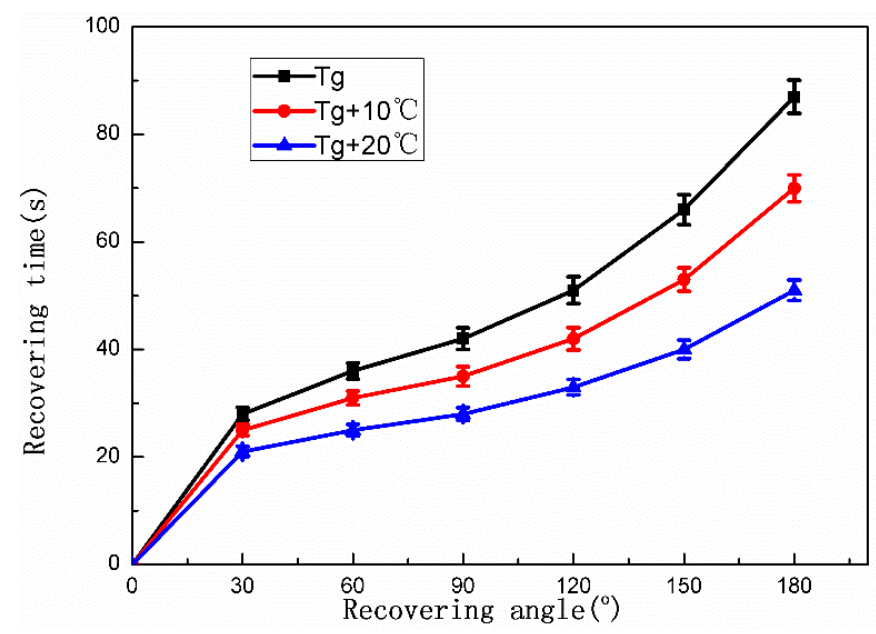

Figure 9. Relationship between recovering angle and recovering time of $12 \mathrm{wt} \% \mathrm{SiCw} /$ hydro-epoxy composite at different temperatures.

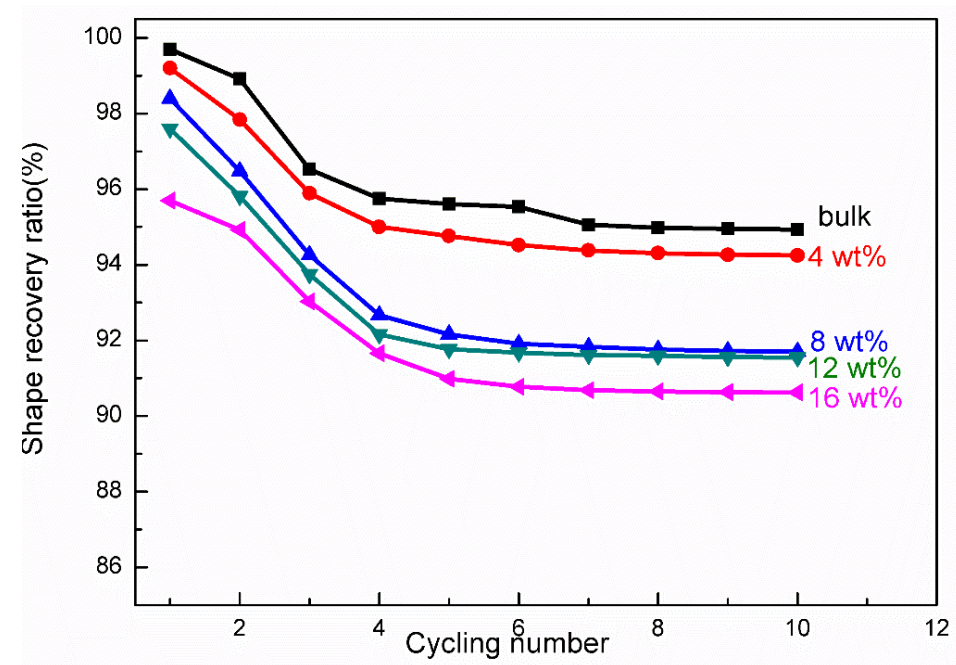

Figure 10. Effects of cycling number on recovery ratio of SiCw/hydro-epoxy composites.

\section{Conclusions}

A series of thermo-induced shape memory $\mathrm{SiCw} /$ hydro-epoxy composites were fabricated. Due to the reinforcement of the $\mathrm{SiCws}$, the mechanical properties of the $\mathrm{SiCw} /$ hydro-epoxy composites were improved by $64.1 \%$ when $\mathrm{SiCw}$ content was $12 \mathrm{wt} \%$. With increasing $\mathrm{SiCw}$ content, the shape memory transition temperatures of the $\mathrm{SiCw} /$ hydro-epoxy composites slightly decreased, but thermal conductivity increased. The additional $\mathrm{SiCws}$ improved the shape fixity ratio of $\mathrm{SiCw} /$ hydro-epoxy composites, but the shape recovery ratio significantly decreased because the SiCws do not have shape memory effect. The shape recovery speed increased with the increase in test temperature. Though the cycling times have a disadvantageous effect on shape memory behavior, the shape recovery ratio of the composites is higher than $90 \%$.

Acknowledgments: This work supported by Research Program supported by the National Natural Science Foundation of China (61176130, 51305320 and 51675397), the Ningbo Natural Science Foundation (2016A610030), the 60 class General Financial Grant from the China Postdoctoral Science Foundation (2016M600765), and the Fundamental Research Funds for the Central Universities of China (JB150408 and K5051304003).

Author Contributions: Yongkun Wang and Junjie Ye conceived and designed the experiments; Yongkun Wang and Xiaohan Liu performed the experiments; Yongkun Wang and Wen Chao Tian analyzed the data; Yongkun Wang wrote the paper. 
Conflicts of Interest: The authors declare no conflict of interest.

\section{References}

1. Zhao, Q.; Qi, H.J.; Xie, T. Recent progress in shape memory polymer: New behavior, enabling materials, and mechanistic understanding. Prog. Polym. Sci. 2015, 49, 79-102. [CrossRef]

2. Michal, B.T.; Spencer, E.J.; Rowan, S.J. Stimuli-responsive reversible two-level adesion from structural dynamic shpe memory polymer. ACS Appl. Mater. Inters. 2016, 8, 11041-11049. [CrossRef] [PubMed]

3. Meng, H.; Li, G.Q. A review of stimuli-responsive shape memory polymer composites. Polymer 2013, 54, 2199-2221. [CrossRef]

4. Liu, Y.J.; Du, H.Y.; Liu, L.W.; Leng, J.S. Shape memory polymers and their composites in aerospace applications: A review. Smart Mater. Struct. 2014, 23, 023001. [CrossRef]

5. Sun, L.; Huang, W.M.; Ding, Z.; Zhao, Y.; Wang, C.C.; Purnawali, H.; Tang, C. Stimulus-responsive shape memory materials: A review. Mater. Des. 2012, 33, 577-640. [CrossRef]

6. Wang, Y.K.; Tian, W.C.; Xie, J.Q.; Liu, Y. Thermoelectric responsive shape memory graphene/hydro-epoxy composites for actuators. Micromachines 2016, 7, 145. [CrossRef]

7. Zhao, Q.; Marc, B.; Lendlein, A. Shape-memory polymers with multiple transitions: Complex actively moving polymers. Soft Matter. 2013, 6, 1744-1755. [CrossRef]

8. Pan, L.; Zhu, X.D.; Xie, X.M.; Liu, Y.T. Smart Hybridization of $\mathrm{TiO}_{2}$ Nanorods and $\mathrm{Fe}_{3} \mathrm{O}_{4}$ Nanoparticles with Pristine Graphene Nanosheets: Hierarchically Nanoengineered Ternary Heterostructures for High-Rate Lithium Storage. Adv. Funct. Mater. 2015, 25, 3341-3350. [CrossRef]

9. Wang, Y.K.; Zhu, G.M.; Xie, J.Q.; Meng, Q.N.; Liu, T.T.; Ren, F. Mechanical and shape memory behavior of chemically cross-linked SBS/LDPE blends. J. Polym. Res. 2014, 21, 3. [CrossRef]

10. Lv, H.B.; Yao, Y.T.; Huang, W.M.; Leng, L.S.; Hui, D. Significantly improving infrared light-induced shape recovery behavior of shape memory polymeric nanocomposite via a synergistic effect of carbon nanotube and boron nitride. Compos. Part B Eng. 2014, 62, 256-261.

11. Jiang, Y.; Fang, L.; Kratz, K.; Lendlein, A. Influence of Compression Direction on the Shape-Memory Effect of Micro-Cylinder Arrays Prepared from Semi-Crystalline Polymer Networks. MRS Adv. 2016, 27, 1985-1993. [CrossRef]

12. Wang, Y.K.; Zhu, G.M.; Cui, X.P.; Liu, T.T.; Liu, Z.; Wang, K. Electroactive shape memory effect of radiation cross-linked SBS/LLDPE composites filled with carbon black. Colloid Polym. Sci. 2014, 292, 2311-2317. [CrossRef]

13. Ghosh, P.; Rao, A.; Srinivasa, A.R. Design of multi-state and smart-bias components using shape memory alloy and shape memory polymer composites. Mater. Design 2013, 44, 164. [CrossRef]

14. Li, G.Q.; Ajisafe, O.; Meng, H. Effect of strain hardening of shape memory polymer fibers on healing efficiency of thermosetting polymer composites. Polymer 2013, 54, 920-928. [CrossRef]

15. Fang, L.; Fang, T.Y.; Liu, X.X.; Chen, S.P.; Lu, C.H.; Xu, Z.Z. Near-Infrared Light Triggered Soft Actuators in Aqueous Media Prepared from Shape-Memory Polymer Composites. Macromol. Mater. Eng. 2016, $301,1111$. [CrossRef]

16. Wang, Y.K.; Tian, W.C.; Zhu, G.M.; Xie, J.Q. Thermomechanical and shape memory properties of SCF/SBS/LLDPE composites. Chin. J. Polym. Sci. 2016, 34, 1354-1362.

17. Ecker, M.; Pretsch, T. Multifunctional poly (ester urethane) laminates with encoded information. RSC Adv. 2014, 4, 286. [CrossRef]

18. Ecker, M.; Pretsch, T. Novel design approaches for multifunctional information carriers. RSC Adv. 2014, 4, 46680. [CrossRef]

19. Ecker, M.; Pretsch, T. Durability of switchable QR code carriers under hydrolytic and photolytic conditions. Smart Mater. Struct. 2013, 22, 094005. [CrossRef]

20. Purnwali, H.; Xu, W.W.; Zhao, Y.; Ding, Z.; Wang, C.C.; Huang, W.M.; Fan, H. Poly (methyl methacrylate) for active disassembly. Smart Mater. Struct. 2012, 21, 075006. [CrossRef]

21. Fritzsche, N.; Pretsch, T. Programming of temperature-memory onsets in a semicrystalline polyurethane elastomer. Macromolecules 2014, 47, 5952-5959. [CrossRef] 
22. Ma, L.; Zhao, J.; Wang, X.Y.; Chen, M.; Liang, Y.R.; Wang, Z.W.; Yu, Z.N.; Hedden, R.C. Effects of carbon black nanoparticles on two-way reversible shape memory in crosslinked polyethylene. Polymer 2015, 56, 490-497. [CrossRef]

23. Park, J.H.; Dao, T.D.; Lee, H.; Jeong, H.M.; Kim, B.K. Properties of graphene/shape memory thermoplastic polyurethane composites actuating by various methods. Materials 2014, 7, 1520-1538. [CrossRef]

24. Wang, M.C.; Miao, R.; He, J.K.; Xu, X.Q.; Liu, J.C.; Du, H.Y. Silicon Carbide whiskers reinforced polymer-based adhesive for joining C/C composites. Mater. Des. 2016, 99, 293-302. [CrossRef]

25. Wang, Q.H.; Li, Y.W.; Jin, S.L.; Sang, S.B. Catalyst-free hybridization of silicon carbide whiskers and expanded graphite by vapor deposition method. Ceram. Int. 2015, 41, 14359-14366. [CrossRef]

26. Yuan, Z.K.; Yu, J.H.; Rao, B.L.; Jiang, N.; Gao, J.; Lu, S.R. Enhanced Thermal Properties of Epoxy Composites by Using Hyperbranched Aromatic Polyamide Grafted Silicon Carbide Whiskers. Macromol. Res. 2014, 22, 405-411. [CrossRef]

27. Kumar, K.S.S.; Biju, R.; Nair, C.P.R. Progress in shape memory epoxy resins. React. Funct. Polym. 2013, 73, 421. [CrossRef]

28. Wang, Y.K.; Zhu, G.M.; Tang, Y.S.; Liu, T.T.; Xie, J.Q.; Ren, F. Short glass fiber reinforced radiation crosslinked shape memory SBS/LLDPE blends. J. Appl. Polym. Sci. 2014, 131, 40691.

29. Suchanek, W.; Yashima, M.; Kakihana, M.; Yoshimura, M. Hydroxyapatite/hydroxyapatite-whisker composites without sintering additives: Mechanical properties and microstructural evolution. J. Am. Ceram. Soc. 1997, 80, 2805. [CrossRef]

30. Gu, J.W.; Meng, X.D.; Tang, Y.S.; Li, Y.; Zhuang, Q.; Kong, J. Hexagonal boron nitride/silicone rubber dielectric thermally conductive composites with excellent thermal stabilities. Compos. Part A Appl. Sci. Manuf. 2017, 92, 27-32. [CrossRef]

31. Wen, L.Z.; Xiao, P.; Li, Z.; Yu, X.Y.; Li, Y. Thermal cycling behavior and oxidation resistance of SiC whisker-toughened-mullite/SiC coated carbon/carbon composites in burner rig tests. Corros. Sci. 2016, $106,179$.

32. Sabbaghianrad, S.; Langdon, T.G. Developing superplasticity in an aluminum matrix composite processed by high-pressure torsion. Mater. Sci. Eng. A Struct. 2016, 655, 36-43. [CrossRef]

33. Wang, K.; Zhu, G.M.; Ren, F.; Yan, X.G.; Cui, X.P. The effect of carbon fiber on electroactive shape memory behaviors of cyanate-polybutadiene epoxy-carbon black composites. J. Reinf. Plast. Comp. 2016, 35, 556. [CrossRef]

(C) 2017 by the authors; licensee MDPI, Basel, Switzerland. This article is an open access article distributed under the terms and conditions of the Creative Commons Attribution (CC BY) license (http:/ / creativecommons.org/licenses/by/4.0/). 